\title{
Biphasic Cholinergic Synaptic Transmission Controls Action Potential Activity in Thalamic Reticular Nucleus Neurons
}

\author{
Yan-Gang Sun, ${ }^{1}$ Juan D. Pita-Almenar, ${ }^{1}$ Chia-Shan Wu, ${ }^{2}$ John J. Renger, ${ }^{3}$ Victor N. Uebele, ${ }^{3}$ Hui-Chen Lu, ${ }^{2}$ \\ and Michael Beierlein ${ }^{1}$ \\ ${ }^{1}$ Department of Neurobiology and Anatomy, University of Texas Medical School, Houston, Texas 77030, ${ }^{2}$ The Cain Foundation Laboratories, Jan and Dan \\ Duncan Neurological Research Institute, Department of Pediatrics, Baylor College of Medicine, Houston, Texas 77030, and ${ }^{3}$ Merck Research Laboratories, \\ West Point, Pennsylvania 19486
}

Cholinergic neurons in the basal forebrain and the brainstem form extensive projections to a number of thalamic nuclei. Activation of cholinergic afferents during distinct behavioral states can regulate neuronal firing, transmitter release at glutamatergic and GABAergic synapses, and synchrony in thalamic networks, thereby controlling the flow of sensory information. These effects are thought to be mediated by slow and persistent increases in extracellular ACh levels, resulting in the modulation of populations of thalamic neurons over large temporal and spatial scales. However, the synaptic mechanisms underlying cholinergic signaling in the thalamus are not well understood. Here, we demonstrate highly reliable cholinergic transmission in the mouse thalamic reticular nucleus (TRN), a brain structure essential for sensory processing, arousal, and attention. We find that ACh release evoked by low-frequency stimulation leads to biphasic excitatory-inhibitory (E-I) postsynaptic responses, mediated by the activation of postsynaptic $\alpha 4 \beta 2$ nicotinic ACh receptors (nAChRs) and M2 muscarinic ACh receptors (mAChRs), respectively. In addition, ACh can bind to mAChRs expressed near cholinergic release sites, resulting in autoinhibition of release. We show that the activation of postsynaptic nAChRs by transmitter release from only a small number of individual axons is sufficient to trigger action potentials in TRN neurons. Furthermore, short trains of cholinergic synaptic inputs can powerfully entrain ongoing TRN neuronal activity. Our study demonstrates fast and precise synaptic E-I signaling mediated by ACh, suggesting novel computational mechanisms for the cholinergic control of neuronal activity in thalamic circuits.

\section{Introduction}

Neurons in the thalamic reticular nucleus (TRN) are exclusively GABAergic and project to first-order and second-order thalamic nuclei in the dorsal thalamus (Pinault, 2004; Jones, 2007). The TRN is hypothesized to engage in a number of diverse processes, such as sensory information processing (Hartings et al., 2003), attention (Crick, 1984; McAlonan et al., 2006), and the generation of synchronous activity in the thalamocortical system (Kim et al., 1997). However, our understanding of the properties of the

Received July 3, 2012; revised Nov. 28, 2012; accepted Dec. 4, 2012.

Author contributions:Y.-G.S., J.D.P.-A., J.J.R., V.N.U., H.-C.L., and M.B. designed research; Y.-G.S., J.D.P.-A., and C.-S.W. performed research; J.J.R. and V.N.U. contributed unpublished reagents/analytic tools; Y.-G.S., J.D.P.-A., C.-S.W., H.-C.L., and M.B. analyzed data; Y.-G.S., J.D.P.-A., C.-S.W., H.-C.L., and M.B. wrote the paper.

This work was supported in part by funds from the National Institute on Drug Abuse (Grant DA029381) and the National Institute of Child Health and Human Development (Grant HD065561) to H.-C.L.; and the National Institute of Neurological Disorders and Stroke (Grant NS077989), the American Heart Association, the Whitehall Foundation, and the Epilepsy Foundation to M.B. We thank Drs. Adam Carter and Jay Gibson for comments on a previous version of the manuscript, the Baylor Intellectual and Developmental Disabilities Research Center core facility (National Institutes of Health HD024064) for confocal microscopy access, and Dr. Tibor Harkany for providing us with brain tissue of cholinergic neuron reporter mice.

V.N.U. and J.J.R. are employees of Merck \& Co., Inc., and potentially own stock and/or stock options in the company.

Correspondence should be addressed to Michael Beierlein, Department of Neurobiology and Anatomy, University of Texas Medical School, 6431 Fannin, Suite 7.046, Houston, TX 77030. E-mail: michael.beierlein@uth.tmc.edu.

Y.-G. Sun's present address: Institute of Neuroscience, Chinese Academy of Sciences, Shanghai 200031 , China. DOI:10.1523/JNEUROSCI.3177-12.2013

Copyright $\odot 2013$ the authors $\quad 0270-6474 / 13 / 332048-12 \$ 15.00 / 0$ various types of inputs contacting TRN neurons, as well as the postsynaptic integration of these inputs in the dendrites of TRN neurons, is still limited. Such knowledge is critical to gaining a better understanding of the role played by TRN in different types of computational tasks.

TRN neurons are the target of several types of neuromodulatory systems (McCormick, 1989, 1992). Chief among them are cholinergic inputs that originate from two distinct sources, the nucleus basalis of the forebrain and the pedunculopontine tegmental and laterodorsal tegmental nuclei of the brainstem. The release of acetylcholine $(\mathrm{ACh})$ from cholinergic afferents is thought to control the firing modes in both TRN and thalamic relay neurons (McCormick and Bal, 1997), primarily by binding to muscarinic acetylcholine receptors ( $\mathrm{mAChRs}$ ) and, to a lesser extent, nicotinic acetylcholine receptors (nAChRs). However, cholinergic control of neuronal excitability has been primarily examined using exogenous agonists and antagonists (Lee and McCormick, 1995). Little is known about the mode of cholinergic signaling under physiological conditions. In vivo work in the TRN has demonstrated short-latency postsynaptic signals in response to stimulation of cholinergic afferents from the brainstem (Hu et al., 1989), consistent with signaling via conventional synapses. However, the majority of release sites formed by cholinergic afferents do not appear to be closely associated with dendrites of TRN neurons (Parent and Descarries, 2008). Furthermore, the changes in membrane potential evoked by cholin- 
ergic afferent stimulation can be long-lasting (Hu et al., 1989), consistent with a slow breakdown of ACh far from sites of release. Together, this would argue that cholinergic afferent activity in the TRN does not directly engage in precise computational roles, but instead modulates network function on larger temporal and spatial scales, similar to what has been postulated for other brain areas (Descarries et al., 1997).

Our results, obtained using mouse somatosensory thalamic slices, strongly challenge this view. We show that the release of $\mathrm{ACh}$ from individual cholinergic axons leads to reliable biphasic excitatory-inhibitory (E-I) responses in TRN neurons, mediated by the rapid activation of postsynaptic nAChRs and mAChRs, respectively. Furthermore, we find that cholinergic inputs activated at $10 \mathrm{~Hz}$ can rapidly and reliably entrain TRN neuronal firing. Thus, rather than acting exclusively as a slow neuromodulator, ACh can precisely control postsynaptic activity in individual TRN neurons.

\section{Materials and Methods}

Slice preparation. Thalamocortical slices $(400 \mu \mathrm{m})$ were prepared from both male and female C57BL/6 mice (P13-P20) as described previously (Agmon and Connors, 1991). Animals were anesthesized with isofluorane and decapitated, following procedures in accordance with $\mathrm{NIH}$ guidelines and approved by the University of Texas Health Science Center at Houston animal welfare committee. Slices were cut in an ice-cold sucrose-containing solution consisting of (in mM): 234 sucrose, $2.5 \mathrm{KCl}$, $1.25 \mathrm{NaH}_{2} \mathrm{PO}_{4}, 10 \mathrm{MgSO}_{4}, 26 \mathrm{NaHCO}_{3}, 10$ glucose, and $0.5 \mathrm{CaCl}_{2}$, saturated with $95 \% \mathrm{O}_{2}-5 \% \mathrm{CO}_{2}$, using a vibratome (Leica VT1200S) at slicing speeds of $0.2 \mathrm{~mm} / \mathrm{s}$ and a blade vibration amplitude of $0.8 \mathrm{~mm}$. Slices were incubated at $34^{\circ} \mathrm{C}$ for $40 \mathrm{~min}$ in saline solution containing (in mm): $126 \mathrm{NaCl}, 26 \mathrm{NaHCO}_{3}, 2.5 \mathrm{KCl}, 1.25 \mathrm{NaH}_{2} \mathrm{PO}_{4}, 10$ glucose, 2 $\mathrm{CaCl}_{2}$, and $2 \mathrm{MgCl}_{2}$. Slices were then kept at room temperature before recordings.

Electrophysiology. Slices were placed on glass coverslips coated with poly-L-lysine (Sigma-Aldrich) and submerged in a recording chamber (Warner Instruments). All experiments were performed at $32-34^{\circ} \mathrm{C}$ using an in-line heater while perfusing the recording chamber with solution at $3-4 \mathrm{ml} / \mathrm{min}$ using a Minipulse 3 pump (Gilson). Unless noted, experiments were performed in the presence of NBQX $(10 \mu \mathrm{M}), 3-[(R)-2$ carboxypiperazin-4-yl]-propyl-1-phosphonic acid (R-CPP, $5 \mu \mathrm{M}$ ), picrotoxin $(50 \mu \mathrm{M})$, and CGP55845 $(5 \mu \mathrm{M})$ to block AMPA, NMDA, $\mathrm{GABA}_{\mathrm{A}}$, and $\mathrm{GABA}_{\mathrm{B}}$ receptors, respectively. Recordings were obtained under infrared-differential interference contrast visualization using an Olympus BX51WI microscope (Olympus Optical) and a CCD camera (Hamamatsu).

For whole-cell voltage-clamp recordings, recording pipettes were filled with an internal solution containing (in mM): $120 \mathrm{CsMeSO}_{3}, 10$ CsCl, 10 HEPES, 11 EGTA, $1 \mathrm{MgCl}_{2}, 1 \mathrm{CaCl}_{2}, 2 \mathrm{Mg}$-ATP, $0.3 \mathrm{Na}$-GTP, and 1 QX-314, adjusted to $295 \mathrm{mOsm}$ and $\mathrm{pH}$ 7.3. Whole-cell currentclamp recordings from TRN neurons were obtained with an internal solution containing (in mM): 108 KGluc, $26 \mathrm{KCl}, 10 \mathrm{HEPES}, 0.5$ EGTA, 2 $\mathrm{MgCl}_{2}, 0.16 \mathrm{CaCl}_{2}, 2 \mathrm{Mg}$-ATP, and $0.4 \mathrm{Na}$-GTP, adjusted to $295 \mathrm{mOsm}$ and $\mathrm{pH}$ 7.3. Loose-patch recordings were obtained in voltage clamp with pipettes (2-3 M $\Omega$ ) filled with ACSF, and the seal resistance was $20-100 \mathrm{M} \Omega$. To minimize any influence on the membrane potential of the recorded cell, holding potential was continually monitored and adjusted to keep the holding current near 0 pA (Perkins, 2006). Extracellular stimuli were evoked every $12 \mathrm{~s}$ with patch pipettes (5-8 $\mu \mathrm{m}$, tip diameter) filled with ACSF and placed into the TRN (100$200 \mu \mathrm{m}$ from the recorded cell). Stimulation intensities ranged from 10 to $30 \mu \mathrm{A}$ (stimulus duration, $200 \mu \mathrm{s}$ ), unless noted otherwise.

Physostigmine, dihydro- $\beta$-erythroidine hydrobromide ( $\mathrm{DH} \beta \mathrm{E}), \mathrm{AF}-\mathrm{DX}$ 116, nicotine ditartrate, methyllycaconitine citrate (MLA), PNU 120596, R-CPP, NBQX, picrotoxin, and CGP55845 were purchased from Tocris Cookson. TTA-P2 was obtained from Merck Research Laboratories. All other chemicals were obtained from Sigma-Aldrich.
Data acquisition and analysis. Data were acquired using pClamp software (Molecular Devices). Recordings were filtered at $2-10 \mathrm{kHz}$ and digitized at $20 \mathrm{kHz}$ with a 16-bit analog-to-digital converter (Digidata 1440A, Molecular Devices). Data analysis was performed with custom macros written in Igor Pro (Wavemetrics). Response amplitude variability was measured as the coefficient of variation (CV). Noise-corrected values for the $\mathrm{CV}$ were computed as follows: square root of (variance signal $_{-}$ variance $\left._{\text {noise }}\right) /$ mean $_{\text {signal }}$. Noise was measured from the baseline just before the stimulation by using the same fixed time window as for the response. Statistical test were performed with the unpaired or paired Student's $t$ test. Differences are considered to be significant at $p<0.05$. Data are presented as mean \pm SEM.

Immunohistochemistry. The generation, genotyping, and characterization of cholinergic neuron reporter mice have been described previously (Tallini et al., 2006). Briefly, transgenic mice were engineered to express eGFP under the control of choline acetyltransferase (ChAT) transcriptional regulatory elements. This was accomplished by introducing a modified bacterial artificial chromosome spanning the endogenous ChAT locus, in which the EGFP cassette was inserted at the initiation codon of the ChAT gene. Immunohistochemical staining was performed as described previously (Wu et al., 2010). Brains were sectioned coronally into $50-\mu \mathrm{m}$-thick sections with a Leica VT1000S vibrating microtome. Two primary antibodies, rat anti-M2 muscarinic acetylcholine receptor (1:1000, Millipore) and chicken anti-GFP (1:2000, Aves Labs), were used. Fluorescent signals for M2 muscarinic acetylcholine receptors and GFP were detected by using the secondary antibodies goat anti-rat IgGDylight 594 (1:500, Jackson ImmunoResearch Laboratories) and goat anti-chicken IgG-Alexa 488 (1:500, Invitrogen), respectively. Confocal images were obtained using a Zeiss 510 system.

\section{Results}

\section{Release of ACh elicits EPSCs in TRN neurons by activating $\alpha 4 \beta 2$ nAChRs}

To examine the mechanisms underlying cholinergic neurotransmission, we performed whole-cell voltage-clamp recordings from GABAergic neurons in the TRN in thalamocortical slices of mice. Experiments were initially performed in the presence of R-CPP, picrotoxin, and CGP55845 to block NMDARs, $\mathrm{GABA}_{\mathrm{A}} \mathrm{Rs}$, and $\mathrm{GABA}_{\mathrm{B}} \mathrm{Rs}$, respectively, and TRN neurons were recorded with a Cs-based internal solution (Fig. $1 A$ ). Single stimuli applied locally in the TRN led to EPSCs with two distinct components. In the example shown in Figure $1 B$, the fast EPSC (latency, $1.1 \mathrm{~ms} ; 20-80 \%$ rise time, $0.4 \mathrm{~ms}$; decay time constant, $1.6 \mathrm{~ms}$ ) was blocked by the AMPAR antagonist NBQX, indicating activation of glutamatergic synapses formed by both thalamic and neocortical afferents. The remaining EPSC had much slower kinetics (latency, $3.5 \mathrm{~ms} ; 20-80 \%$ rise time, $10.8 \mathrm{~ms}$; decay time constant, $123.6 \mathrm{~ms}$ ) and was blocked by the nAChR antagonist $\mathrm{DH} \beta \mathrm{E}(3 \mu \mathrm{M})$. Consistently, the nonspecific nAChR antagonist hexamethonium $(100 \mu \mathrm{M})$ also blocked isolated slow EPSCs (Fig. $1 H)$. Slow EPSCs were dependent on action potential activity and were completely blocked by TTX (500 nm, Fig. $1 H)$. Thus, the release of ACh evoked by individual stimuli reliably triggered nAChR-mediated EPSCs (nEPSCs) in TRN neurons. All experiments described below except those shown in Figure 2 were performed in the presence of both glutamatergic and GABAergic receptor antagonists to isolate cholinergic responses.

Nicotinic AChRs expressed throughout the brain primarily exist as $\alpha 4 \beta 2$ heteropentamers or $\alpha 7$ homopentamers (Dani and Bertrand, 2007; Miwa et al., 2011). These two nAChR subtypes are often coexpressed in postsynaptic membranes and display dramatically distinct kinetics and pharmacological properties (Dani and Bertrand, 2007). To determine their relative contribution in mediating the nEPSC in TRN neurons, we used subtypespecific antagonists and modulators. We found that bath 
application of $300 \mathrm{~nm} \mathrm{DH} \beta \mathrm{E}$, which at this concentration selectively blocks $\alpha 4 \beta 2$ nAChRs, largely eliminated nEPSCs $(157.6 \pm 25.1 \mathrm{pA}$ in control, $13.8 \pm 2.7 \mathrm{pA}$ in $\mathrm{DH} \beta \mathrm{E}, p<0.001, n=8$, Fig. $1 C, D, H)$. By contrast, the $\alpha 7$ nAChR selective antagonist MLA (50 nM) only moderately decreased nEPSCs (Fig. 1H). Furthermore, bath application of the $\alpha 7$ nAChR-specific allosteric modulator PNU $120596(10 \mu \mathrm{M})$, which enhances EPSCs mediated by $\alpha 7 \mathrm{nAChRs}$ (Hurst et al., 2005), had no effect on nEPSC amplitudes (124.8 $\pm 18.0 \mathrm{pA}$ in control, $122.4 \pm 16.6 \mathrm{pA}$ in PNU 120596, $p=$ 0.72 , Fig. $1 H)$. Compared with $\alpha 7$ nAChRs, $\alpha 4 \beta 2$ nAChRs have a relatively high affinity for agonist activation and show substantial desensitization in the presence of low concentrations $(<500$ nM) of nicotine (Dani and Bertrand, 2007). We found that bath application of nicotine (100 nM) significantly attenuated nEPSCs (Fig. 1H). Together, our data indicate that nEPSCs in the TRN are largely if not entirely mediated by activation of $\alpha 4 \beta 2 \mathrm{nAChRs}$.

The time course of released $\mathrm{ACh}$ is controlled by diffusion and breakdown via acetylcholinesterase (AChE). To determine the role of AChE activity in shaping nEPSC kinetics, we applied the AChE inhibitor physostigmine $(10 \mu \mathrm{M})$ in the presence of atropine to block mAChRs (see below). Physostigmine significantly prolonged the nEPSC decay time constant (302.2 $\pm 38.9 \mathrm{~ms}$ in control, $2381.4 \pm$ $352.5 \mathrm{~ms}$ in physostigmine; $p<0.01, n=$ 5, Fig. $1 E-G)$, indicating that $\mathrm{AChE}$ controls the time course of nAChR activation under physiological conditions. Physostigmine application also led to a significant decrease in nEPSC amplitude $(172.8 \pm 15.6 \mathrm{pA}$ in control, $77.4 \pm 6.1 \mathrm{pA}$ in physostigmine; $p<0.01, n=5$ ), likely due to $\mathrm{nAChR}$ desensitization caused by increases in ambient ACh levels.

Recent studies have demonstrated the synaptic release of glutamate from cholinergic neurons (Higley et al., 2011; Ren et al., 2011). To test for potential corelease of glutamate and ACh from the same afferents targeting TRN, we performed local stimulation at low frequencies in the absence of AMPAR antagonists. Assuming that nAChRs and AMPARs are coexpressed at postsynaptic sites and can be reliably activated following transmitter release from the same axons, the stimulus intensity for recruiting fast AMPAR EPSCs and slow nEPSCs should be the same. However, we found that nEPSCs could be evoked in isolation at low stimulus intensities, with increases in stimulus intensity typically leading to the recruitment of a fast AMPAR EPSC (Fig. 2), strongly suggesting that, in the $n=5-8$.
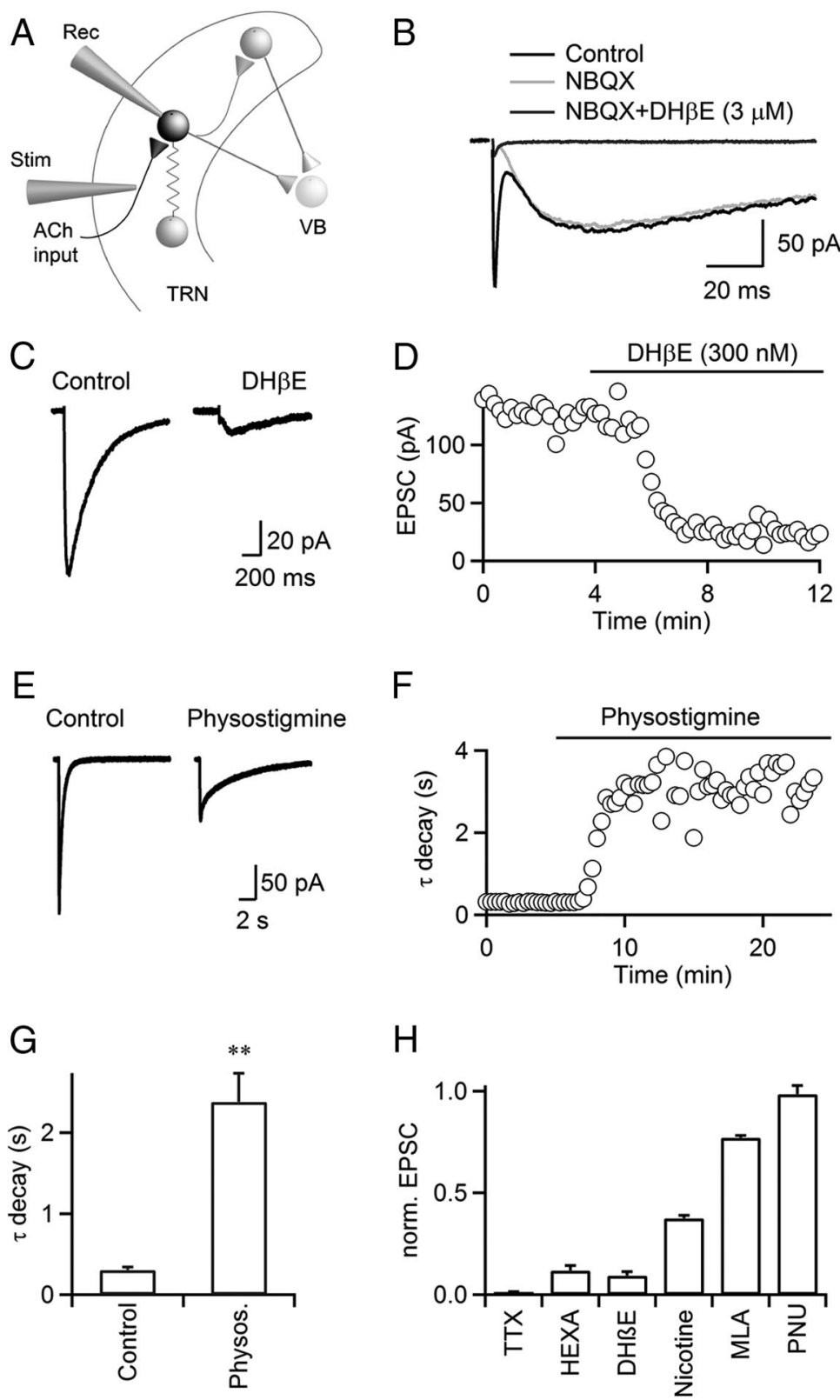

Figure 1. Cholinergic synaptic transmission in the TRN is mediated by $\alpha 4 \beta 2 \mathrm{nAChRs}$. A, TRN neuronal circuit. TRN neurons were recorded with a Cs-based internal solution. Synaptic inputs were activated with a patch pipette (Stim), placed at lateral distances of $100-200 \mu \mathrm{m}$. VB, ventrobasal thalamus; Rec, recording pipette; Stim, stimulus electrode. $\boldsymbol{B}$, For a representative experiment, single stimuli evoked EPSCs with a fast and a slow component (black trace) in a TRN neuron. The fast component was blocked by the AMPAR antagonist NBQX (10 $\mu \mathrm{M}$, gray trace), and the slow component was blocked by the nAChR antagonist $\mathrm{DH} \beta \mathrm{E}(3 \mu \mathrm{M}$, dark gray trace). $\boldsymbol{C}, \boldsymbol{D}$, A representative experiment showing that $\mathrm{nEPS}(\mathrm{s}$ were blocked by low doses of $\mathrm{DH} \beta \mathrm{E}(300 \mathrm{~nm}, \boldsymbol{C})$. Time course of $\mathrm{nESSC}$ amplitude during bath application of $\mathrm{DH} \beta \mathrm{E}(300 \mathrm{~nm})$, for the same cell (D).E, $\boldsymbol{F}$, A representative experiment showing that application of the AChE inhibitor physostigmine $(10 \mu \mathrm{m})$ prolonged $\mathrm{nEPSC}$ decay and reduced $\mathrm{nEPSC}$ amplitude $(\boldsymbol{E})$. Time course of $\mathrm{nEPSC}$ decay during bath application of physostigmine $(10 \mu \mathrm{m}, \boldsymbol{F})$. Decay was fit by a single exponential function. Experiment was performed in the presence of atropine $(10 \mu \mathrm{M})$. G, Summary showing that physostigmine $(10 \mu \mathrm{M})$ increased time constant of $\mathrm{nEPSC}$ decay. $n=5,{ }^{* *} p<0.01$. Paired Student's $t$ test. $\boldsymbol{H}$, Summary showing the effect of TTX ( $\left.500 \mathrm{~nm}\right)$, hexamethonium (HEXA, $100 \mu \mathrm{M}), \mathrm{DH} \beta \mathrm{E}(300 \mathrm{~nm})$, nicotine (100 nM), MLA (50 nM), PNU 120596 (PNU, $10 \mu \mathrm{m}$ ) on nEPSC amplitude, normalized to control.

TRN, glutamate and ACh are liberated from distinct types of synapses.

Postsynaptic M2 mAChRs mediate stimulus-evoked IPSCs TRN neurons express $\mathrm{G}_{\mathrm{i}}$-coupled $\mathrm{M} 2 \mathrm{mAChRs}$ in their dendrites (Oda et al., 2007), whose activation by exogenously applied ACh leads to membrane hyperpolarization (Lee and McCormick, 1995). 
A
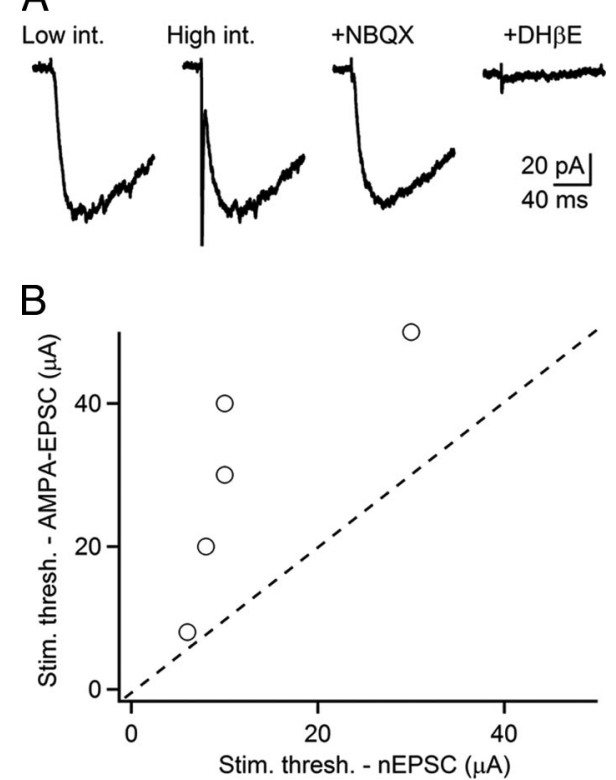

Figure 2. Glutamate and ACh are released from distinct sets of synapses. TRN neurons were recorded in voltage clamp with a Cs-based internal solution in the presence of $R$-CPP, picrotoxin, and CGP55845 to block NMDA, GABA $A^{\prime}$ and $G_{A B A}$ receptors, respectively. $A$, Representative recording showing that low-intensity stimuli trigger $\mathrm{nEPSCS}$, blocked by $\mathrm{DH} \beta \mathrm{E}(3 \mu \mathrm{m})$. Increases in stimulus intensity led to the recruitment of AMPAR EPSCs, blocked by NBQX $(10 \mu \mathrm{M})$, while the $n E P S C$ amplitude remained unchanged. $\boldsymbol{B}$, Summary plot showing distinct thresholds for AMPAR EPSCs and $n E P S C S . n=5$.

However, the dynamics of their activation under physiological conditions are not well understood. In neurons throughout the brain, $\mathrm{mAChRs}$ are thought to be expressed extrasynaptically (Yamasaki et al., 2010) and to respond to slow and widespread increases in extracellular ACh levels, evoked by sustained activation of cholinergic inputs. To explore the conditions leading to the activation of TRN mAChRs, neurons were recorded in voltage clamp with a K-based internal solution. Surprisingly, we found that single stimuli in the TRN evoked biphasic E-I postsynaptic responses, with an early EPSC followed by a late IPSC (Fig. $3 A$ ). As demonstrated above, the EPSC was mediated by nAChR activation and was blocked by $\mathrm{DH} \beta \mathrm{E}(3 \mu \mathrm{M})$. The remaining IPSC had a slow time course (latency, $31.7 \pm 2.6 \mathrm{~ms} ; 20-80 \%$ rise time, $107.6 \pm$ $8.6 \mathrm{~ms}$; decay time constant, $639.0 \pm 102.0 \mathrm{~ms} ; n=5)$ and was largely blocked by the mAChR antagonist atropine $(10 \mu \mathrm{M}$, $40.8 \pm 3.3 \mathrm{pA}$ in control, $7.6 \pm 2.1 \mathrm{pA}$ in atropine, $p<0.01, n=$ 5, Fig. $3 H$ ) and by the selective M2 $\mathrm{mAChR}$ antagonist AF-DX $116(10 \mu \mathrm{M}, 40.8 \pm 9.2 \mathrm{pA}$ in control, $7.2 \pm 2.4 \mathrm{pA}$ in AF-DX 116, $p<0.01, n=7$, Fig. $3 H$ ). E-I responses could be detected in all cells examined and, while the relative contribution of EPSC and IPSC charge to the compound response varied among individual neurons, most responses were dominated by the IPSC (average E/I ratio, $0.54 \pm 0.19$; median E/I ratio, $0.26 ; n=17$, Fig. $3 B$ ). We found that isolated muscarinic IPSCs (muIPSCs) reversed at $-93.2 \pm 0.6 \mathrm{mV}(n=6)$ and displayed a moderate inward rectification (Fig. $3 C, D$ ), indicating the opening of a $\mathrm{K}^{+}$conductance triggered by $\mathrm{M} 2 \mathrm{mAChR}$ activation. Furthermore, muIPSCs significantly curtailed nAChR-mediated excitation, which could be blocked by bath application of AF-DX 116 (Fig. $3 E, F$, left). By contrast, AF-DX 116 did not change the decay of the nEPSC when postsynaptic $\mathrm{K}^{+}$conductances were blocked by recording TRN neurons with Cs-based internal solution (Fig. $3 E, F$, right). Together, these data show that the release of ACh in response to single stimuli can lead to an E-I postsynaptic response, mediated by the activation of $\mathrm{nAChRs}$ and the opening of $\mathrm{a} \mathrm{K}^{+}$conductance, triggered by $\mathrm{mAChR}$ activation, respectively.

We performed additional experiments to characterize the nature of the $\mathrm{K}^{+}$conductance linked to $\mathrm{mAChR}$ activation. The rectification observed for the muIPSC (Fig. 3C,D) is consistent with the opening of a G-protein-coupled inwardly rectifying potassium (GIRK) conductance (Lüscher et al., 1997). In agreement, muIPSCs rapidly attenuated when neurons were dialyzed with an internal solution containing guanosine $5^{\prime}$-[ $\beta$-thio] diphosphate (GDP $\beta S, 1 \mathrm{~mm}$ ) to block postsynaptic G-protein activation (Fig. $3 G, H$ ). Furthermore, bath application of either barium $(200 \mu \mathrm{M})$ or the selective GIRK antagonist tertiapin-Q (200 nM) largely blocked muIPSCs (Fig. 3H). Together, our data suggest that M2 mAChR activation by synaptically released ACh leads to the opening of GIRK conductances in TRN neurons.

\section{Release of ACh from individual cholinergic axons activates both $\mathrm{nAChRs}$ and $\mathrm{mAChRs}$}

While our findings described above clearly demonstrate the existence of fast cholinergic signaling in the TRN, it is possible that the simultaneous activation of many afferents is required to generate postsynaptic responses, raising concerns about their physiological significance. To quantify the impact of ACh release from individual axons, we used minimal stimulation techniques. Using a Cs-based internal solution, we first characterized unitary nEPSCs. Stimulus intensity was adjusted so that single stimuli evoked an approximately equal number of response failures and successes (Fig. 4A,B). Amplitude variability of successful trials was extremely low, suggesting the activation of individual axons. For the experiment shown, a small increase in stimulus intensity completely eliminated all response failures, but did not lead to a significant change in the average amplitude of successes $(92.5 \mathrm{pA}$ at $6.5 \mu \mathrm{A}, 94.9 \mathrm{pA}$ at $9.0 \mu \mathrm{A}$, Fig. $4 B$ ), indicating that additional synaptic inputs were not recruited. Thus, the large majority of response failures observed at lower stimulus intensities likely resulted from a failure of axonal stimulation, rather than a failure of transmitter release. Similar findings were made for five additional unitary inputs (Fig. 4C). While response amplitudes of unitary synaptic inputs varied among cells $(46.7 \pm 11.8 \mathrm{pA}$, ranging from 19.1 to $92.5 \mathrm{pA}, n=6$; Fig. $4 C$, left), the coefficient of variation was generally low $(0.10 \pm 0.01$, ranging from 0.05 to $0.14, n=6)$, and not a single unitary input displayed failures of release (Fig. $4 C$, right). These data suggest that ACh release from single cholinergic axons can trigger large postsynaptic nAChR-dependent responses, mediated at least in part by a high synaptic release probability.

To determine whether release of ACh from individual axons can reliably activate both $\mathrm{nAChRs}$ and $\mathrm{mAChRs}$, we performed minimal stimulation experiments for cells recorded with a K-based internal solution. We found that nEPSCs and muIPSCs evoked at threshold intensities covaried in their successes and failures (i.e., stimuli evoked either a biphasic response or no response at all) (Fig. $4 D, E$ ). Importantly, E-I signaling was observed in all minimal stimulation experiments. While the stimulus intensity required to activate a unitary cholinergic input at threshold was quite variable for different neurons, it was identical for nEPSCs and muIPSCs in a given neuron (Fig. $4 F$ ). Thus, E-I signaling mediated by the activation of postsynaptic nAChRs and mAChRs is present even at the level of individual inputs.

The experiments described above aimed to isolate individual cholinergic afferents. To test whether multiple cholinergic axons 
form functional synapses with individual TRN neurons, we performed recordings using a Cs-based internal solution and measured nEPSC amplitudes evoked by a range of stimulus intensities. As shown for a representative recording (Fig. 4G,H), we found that increases in stimulus intensity resulted in a stepwise increase in nEPSC amplitude, suggesting the recruitment of additional axons at higher stimulus intensities. Similar findings were made in four of four additional experiments. Thus, individual TRN neurons receive convergent input from several distinct cholinergic axons.

\section{Autoinhibition of $\mathrm{ACh}$ release is} mediated by presynaptic M2 mAChRs Transmitter release during ongoing synaptic transmission is often under the control of negative-feedback mechanisms mediated by metabotropic autoreceptors (Deisz and Prince, 1989; Scanziani et al., 1997). The presence of mAChRs near sites of release could allow for autoinhibition of ACh signaling. To test for the existence of mAChRs on cholinergic afferents, we recorded nEPSCs in the TRN using a Csbased internal solution, before and following bath application of low doses of muscarine (Fig. 5A-C). Muscarine $(1 \mu \mathrm{M})$ caused a strong reduction in nEPSC amplitude, which was reversed by the application of the M2 mAChR antagonist AF-DX $116(10 \mu \mathrm{M}, 19.7 \pm 8.4 \%$ of control in muscarine, $96.1 \pm 3.9 \%$ of control in AF-DX 116, $n=5$ ), suggesting that cholinergic afferents express M2 mAChRs near sites of release.

Next, we examined the activation of presynaptic mAChRs via synaptically released ACh, by activating cholinergic afferents using paired pulses $(0.1-5 \mathrm{~Hz})$ before and following application of the M2 mAChR antagonist AF-DX 116 (10 $\mu \mathrm{M}$, Fig. $5 D, E)$. In control conditions, nEPSCs displayed paired-pulse depression $\left(\mathrm{nEPSC}_{2} / \mathrm{nEPSC}_{1}=0.41 \pm 0.05\right.$ at 2 $\mathrm{Hz}, n=5$ ). Following AF-DX 116 application, the amplitude of $\mathrm{nEPSC}_{1}$ remained unchanged (93.6 $\pm 3.0 \%$ of control in AF-DX 116, $n=5$ ), showing that in control conditions release probability was not modulated by ambient levels of ACh (Fig. 5D,E). By contrast, the amplitude of nEPSC $_{2}$ increased by $53.1 \pm$ $18.4 \%(n=5)$, leading to a significant increase in paired-pulse ratio $\left(\mathrm{nEPSC}_{2} /\right.$ EPSC $_{1}=0.41 \pm 0.05$ in control, $0.63 \pm 0.03$ in AF-DX 116, $n=$ $5, p<0.001)$. Changes in paired-pulse ratio following AF-DX 116 application were detected up to an interstimulus interval of $1 \mathrm{~s}$ (Fig. 5F). To rule out a postsynaptic mechanism for the M2 $\mathrm{mAChR}$ antagonist-induced change in paired-pulse plasticity, we

A
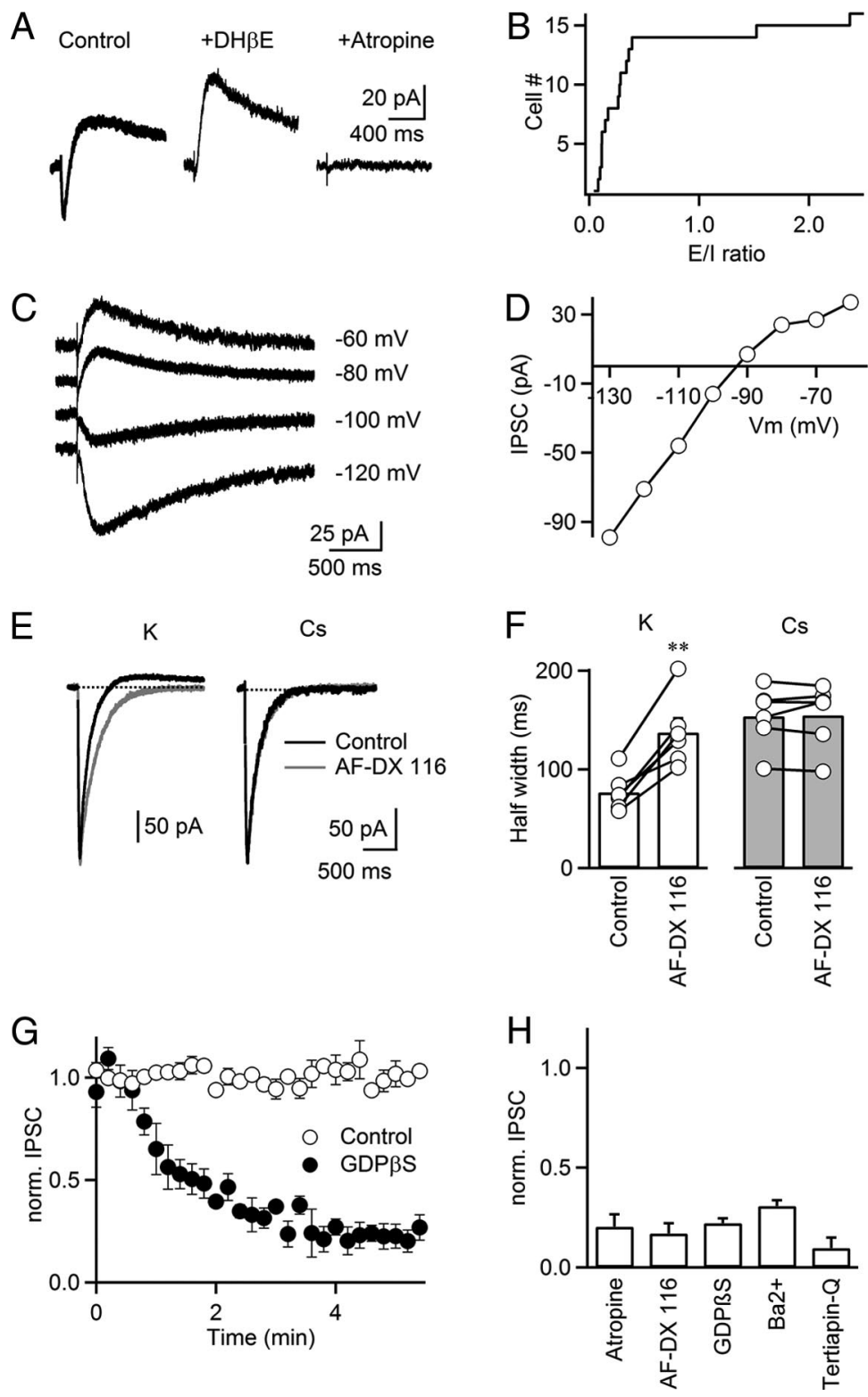

Figure 3. Synaptic activation of M2 mAChRs evokes IPSCs mediated by GIRK channels. TRN neurons were recorded with a K-based internal solution, except in $\boldsymbol{E}$ and $\boldsymbol{F}$. $\boldsymbol{A}$, Biphasic (E-I) postsynaptic response in a TRN neuron, with inward current blocked by the $\mathrm{nAChR}$ antagonist $\mathrm{DH} \beta \mathrm{E}(3 \mu \mathrm{M})$. The remaining outward current was blocked by the mAChR antagonist atropine (10 $\mu \mathrm{m})$. $\boldsymbol{B}$, Plot of the cumulative distribution of $\mathrm{E} / \mathrm{I}$ ratios ( $n=17$ experiments). For biphasic responses, $\mathrm{E}$ was defined as the current integral between $n E P S C$ onset and zero crossing (inward current). I was defined as the current integral following the zero crossing (outward current). C, D, IPSCs display inward rectification. IPSCS were evoked for a range of different holding potentials (C). IPSC amplitudes are plotted against membrane potential for the same neuron (D). $\boldsymbol{E}$, Representative experiments showing cholinergic postsynaptic currents recorded with a K-based internal solution (left) or Cs-based internal solution (right), under control condition (black traces) and following application of AF-DX 116 (10 $\mu \mathrm{m}$, gray traces).F, Summary data plot half width of the nEPSC recorded with a K-based internal solution (left) or a Cs-based internal solution (right) before and following AF-DX 116 (10 $\mu \mathrm{M})$ application. ${ }^{* *} p<0.01$, paired Student's t test. $n=6 . G$, In TRN neurons recorded with an internal solution supplemented with GDP $\beta S(1 \mathrm{~mm})$, isolated mulPSC amplitude strongly attenuated following establishment of whole-cell configuration at $t=0$ (filled circles). Control (open circles) shows recordings without GDP $\beta S$. Experiments were performed in the presence of hexamethonium (100 $\mu \mathrm{m})$ to blocknEPSC. $n=6-7 . \boldsymbol{H}$, Summary showing the effect of atropine $(10 \mu \mathrm{M}), \mathrm{AF}-\mathrm{DX} 116(10 \mu \mathrm{M}), \mathrm{GDP} \beta S(1 \mathrm{~mm}), \mathrm{Ba}^{2+}(200$ $\mu \mathrm{m})$, tertiapin- $Q(200 \mathrm{~nm})$ on the isolated muIPSC amplitude, normalized to control. For tertiapin- $Q$ experiments, cells were held at $\sim-105 \mathrm{mV}$ to measure inward currents. $n=5-7$. repeated these experiments while blocking postsynaptic G-protein signaling by adding GDP $\beta S(1 \mathrm{~mm})$ to the internal solution. Under these conditions, blocking M2 mAChRs by bath application of AF-DX 116 still led to a significant increase in paired-pulse ratio $\left(\mathrm{nEPSC}_{2} / \mathrm{EPSC}_{1}=0.36 \pm 0.02\right.$ in control, 
A
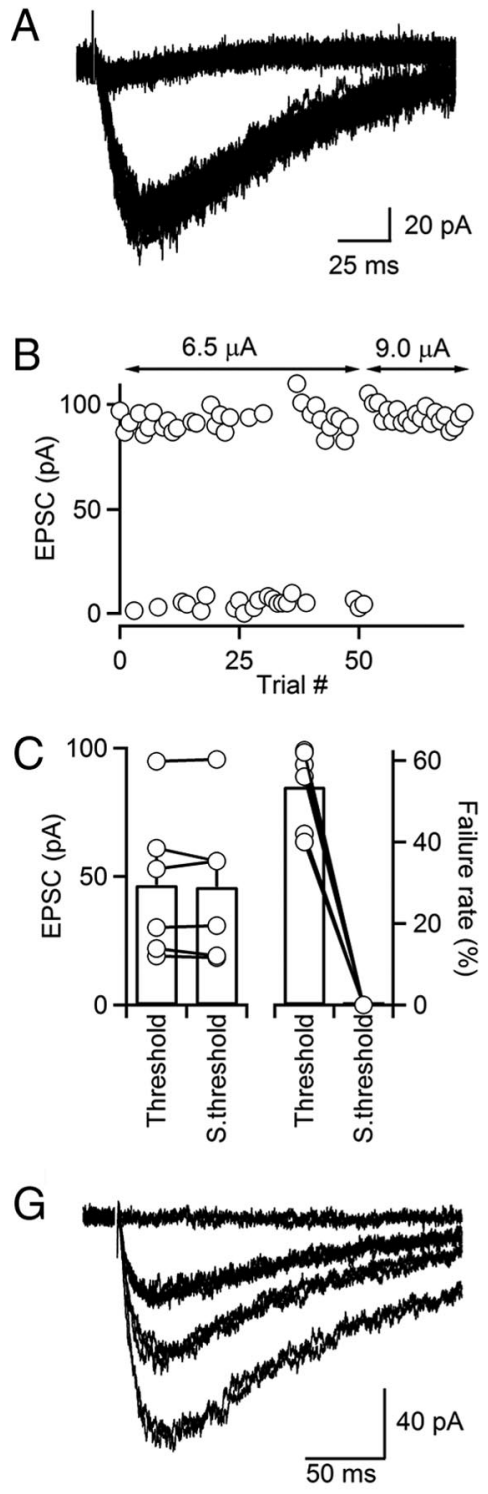

$\mathrm{D}$

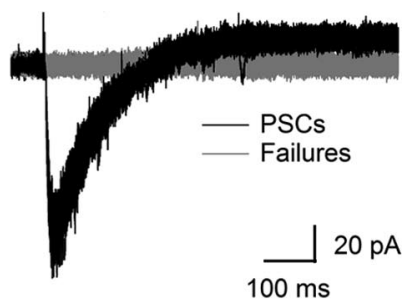

E

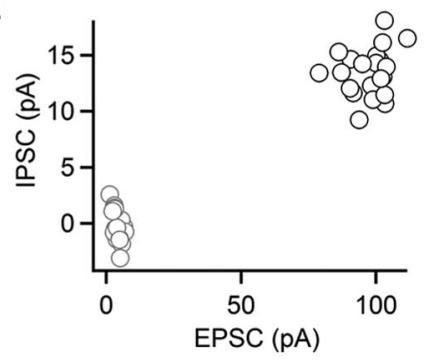

$\mathrm{F}$

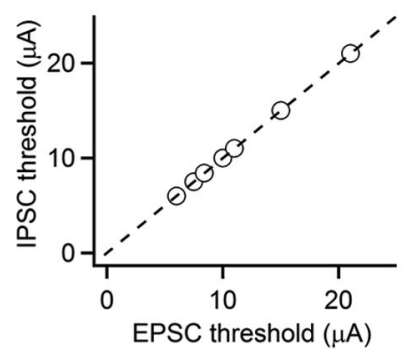

$\mathrm{H}$

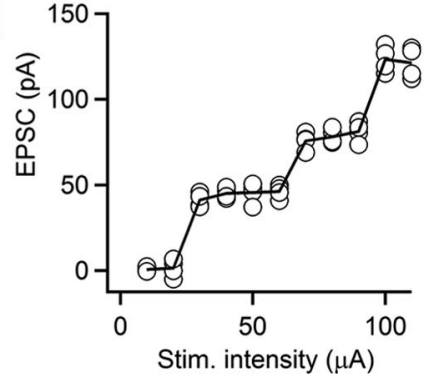

Figure 4. Release of ACh from individual cholinergic axons activates both $n A C h R s$ and $m A C h R s . A-C$, Minimal stimulation of cholinergic inputs. TRN neurons were recorded with a (s-based internal solution. A representative experiment shows overlay of 50 individual trials, including both failures and nEPSCS, evoked at a fixed stimulus intensity $(6.5 \mu \mathrm{A}, A)$. For the same neuron, increases in stimulus intensity from 6.5 to $9.0 \mu$ A resulted in elimination of failures, while the amplitude of $n E P S C s$ in successful trials remained unchanged $(\boldsymbol{B})$. Summary plot showing that unitary $\mathrm{nEPSC}$ amplitude did not change following increase in stimulus intensity ( $p=0.58 ; \boldsymbol{C}$, left). For the same increase in stimulus intensity, failure rate decreased from 53.5 to $0 \%(p<0.001 ; \boldsymbol{C}$, right; $n=6$ cells). $\boldsymbol{D}-\boldsymbol{F}$, ACh release from individual axons activates both $\mathrm{nAChRs}$ and $\mathrm{mAChRs}$. TRN neurons were recorded with a K-based internal solution. Representative experiment shows that stimulation of an individual cholinergic fiber at threshold elicits trials with both $\mathrm{nEPSCS}$ and mulPSCs or failures as shown by overlay of individual trials, evoked for a fixed stimulus intensity (8.4 $\mu A, \boldsymbol{D})$. Graph shows mulPSC amplitude plotted against $\mathrm{nEPSC}$ amplitude for individual trials at threshold $(\boldsymbol{E})$, same data as shown in $\boldsymbol{D}$. Summary plot showing the threshold stimulus intensity necessary to evoke $n E P S C$ and muIPSC. Each point represents data from an individual experiment $(\boldsymbol{F}, n=7) . \boldsymbol{G}, \boldsymbol{H}$, A representative experiment showing $\mathrm{nEPSCS}$ (averages of $4-5$ individual trials) evoked by a series of stimulus intensities (10-110 $\mu \mathrm{A}, 10 \mu \mathrm{A}$ steps, $\boldsymbol{G})$. For the same neuron, graph plots nEPSC amplitudes evoked in individual trials as a function of stimulus intensity $(\boldsymbol{H})$. Neurons were recorded with a Cs-based internal. S.threshold, suprathreshold.

$0.51 \pm 0.03$ in AF-DX 116, $n=5, p<0.01$ ), suggesting that M2 $\mathrm{mAChR}$-mediated changes in paired-pulse plasticity are largely if not entirely presynaptic.

To provide independent evidence for the existence of M2 mAChRs on cholinergic axons, we performed immunostaining for M2 mAChRs in brain sections of mouse, which express GFP in ChATcontaining neurons (Tallini et al., 2006). Abundant M2 mAChR staining was observed in TRN (Fig. 5G,H), while the ventrobasal thalamus was largely devoid of M2 mAChR-positive signal (Fig. 5G,H). Axonal processes containing GFP (Fig. $5 I 1, J 1$, green) often colocalized with punctate M2 mAChR staining (Fig. 5I2,J2, red), strongly suggesting the presence of M2 mAChR on cholinergic axons. Collectively, our data indicate that ongoing cholinergic synaptic transmission is strongly controlled by autoinhibition, mediated by the activation of presynaptic M2 mAChRs.

\section{Presynaptic and postsynaptic M2} mAChRs control nAChR-mediated postsynaptic excitation during stimulus trains

Having established the activation of both presynaptic and postsynaptic M2 mAChRs by ACh following single stimuli, we next quantified their role in regulating $\mathrm{nAChR}$ mediated excitation during short stimulus trains at frequencies $(5-10 \mathrm{~Hz})$ within the range of cholinergic neuronal activity observed in vivo (Boucetta and Jones, 2009). We first examined the role of presynaptic M2 mAChRs in isolation by recording from TRN neurons using a Cs-based internal solution to block IPSCs mediated by postsynaptic M2 mAChRs. In control conditions, nEPSCs showed a moderate short-term depression of stimulus-evoked charge flow ( $5 \mathrm{~Hz}$, Fig. $6 A, B)$. Application of the M2 mAChR antagonist AF-DX 116 $(10 \mu \mathrm{M})$ led to a significant reduction of this depression, confirming that autoinhibition via presynaptic M2 mAChRs regulates the nAChR-dependent postsynaptic excitation during stimulus trains. To estimate the combined effect of both presynaptic and postsynaptic M2 mAChR activation, we repeated these experiments using a K-based internal recording solution. In control conditions, nAChRevoked excitation was rapidly curtailed during a $5 \mathrm{~Hz}$ stimulus train, resulting in a net outward current at steady state (Fig. $6 C, D$, top). Following bath application of the M2 mAChR antagonist AF-DX 116 to block presynaptic and postsynaptic M2 mAChRs, short-term depression of charge flow was entirely eliminated. Similarly, for $10 \mathrm{~Hz}$ stimulus trains, nAChRmediated EPSCs were almost completely depressed at steady state in control conditions (Fig. $6 C, D$, bottom). Bath application of AF-DX 116 completely eliminated depression and revealed slight facilitation of charge flow. These data indicate that activation of both presynaptic and postsynaptic M2 mAChRs leads to a rapid 

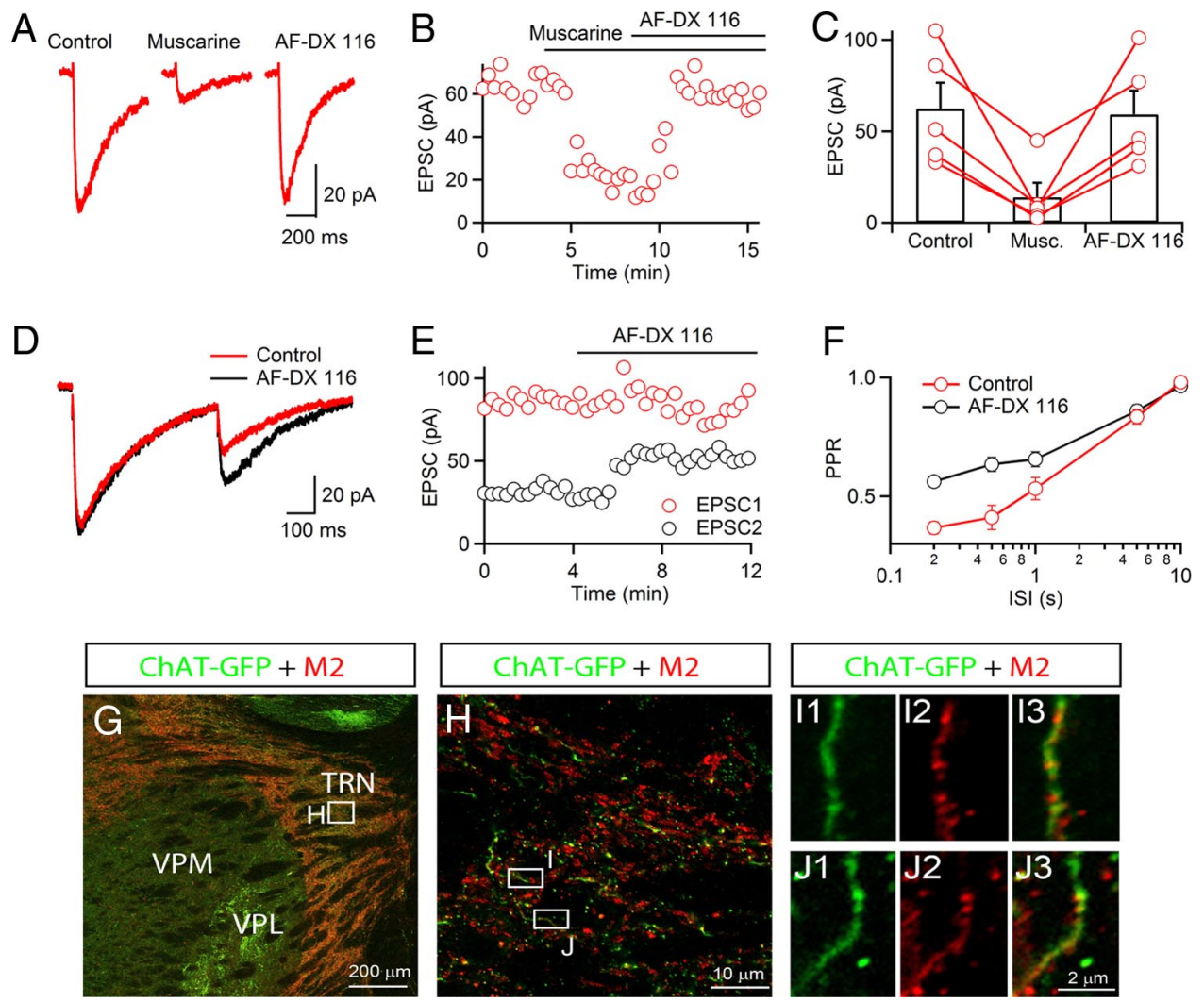

Figure 5. Autoinhibition of ACh release is mediated by presynaptic $M 2 \mathrm{mAChRs}$. Recordings were performed with a Cs-based internal solution. $A$, A representative experiment showing nEPSC suppression by bath application of muscarine $(1 \mu \mathrm{M})$, reversed by the M2 antagonist AF-DX $116(10 \mu \mathrm{M})$. B, For the same neuron, graph plots time course of $n E P S C$ amplitude before and following application of muscarine and AF-DX 116. C, Summary data showing nEPSC suppression by muscarine $(1 \mu \mathrm{M})$, reversed by AF-DX $116(10 \mu \mathrm{M}) . n=5 . D$, nEPSCs evoked by paired stimuli $(500 \mathrm{~ms}$ ISI)

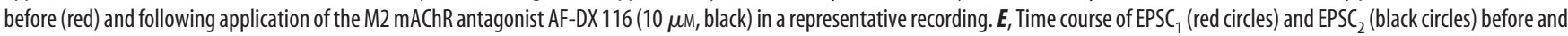
during application of AF-DX $116(10 \mu \mathrm{m})$ for the same neuron as in D.F, Summary showing paired-pulse ratio (EPSC $/$ EPSC $_{1}$ ) for different interstimulus intervals (ISI) in control (red circles) and AF-DX 116 (black circles). $n=5$. G, Immunohistochemical staining in sections from ChAT-GFP reporter mice indicates strong expression of M2 mAChRs in the TRN. Expression of ChAT-GFP was labeled by antibodies against GFP (green) and M2 mAChRs were detected by antibodies against M2 mAChRs (red). $\boldsymbol{H}$, Higher-magnification view for the area indicated in $\boldsymbol{G}$, showing M2 $\mathrm{mAChR}$ is partially overlapping with GFP signal in the TRN. I, J, Examples showing higher-magnification views of the areas indicated in $\boldsymbol{H}$. M2 mAChR-positive signals (I2, J2, red) colocalize with GFP-positive signal $(\mathbf{I 1}, \mathbf{J 1}$, green), as shown in the overlay in $\mathbf{3}$ and $\mathbf{J} \mathbf{3}$. VPM, ventral posteromedial nucleus of thalamus; VPL, ventral posterolateral nucleus of thalamus.

and powerful reduction of nAChR-evoked excitation during ongoing cholinergic activity.

\section{Cholinergic synaptic inputs trigger action potentials in TRN neurons}

Having established that activation of cholinergic fibers induces reliable postsynaptic EPSCs by activating nAChRs, we next examined the impact of cholinergic inputs on TRN neuronal firing. We first performed recordings in cell-attached mode (Perkins, 2006) to minimize perturbations of the intracellular milieu. As shown for a representative experiment (Fig. 7A), single stimuli reliably triggered spike bursts in TRN neurons, which were completely eliminated following bath application of the nAChR antagonist $\mathrm{DH} \beta \mathrm{E}(300 \mathrm{nM})$. Synaptically evoked bursting was observed in all cells examined (4.9 \pm 0.6 spikes, $26.3 \pm 2.9 \mathrm{~ms}$ latency, $n=10)$, and was completely blocked by $\mathrm{DH} \beta \mathrm{E}(5.1 \pm 1.1$ spikes in control, 0 spikes in DH $\beta E, n=5, p<0.01$, Fig. $7 B)$. To estimate the amplitude of nAChR-mediated postsynaptic currents necessary to generate action potentials, we recorded from neurons using a Cs-based internal solution (Fig. 7C). Neurons were first recorded in cell-attached voltage clamp and stimulus intensity was adjusted so that individual stimuli reliably triggered bursts of action potentials (Fig. $7 C$, top). Following establishment of whole-cell configuration, isolated nEPSCs were evoked using the same stimulus intensity (Fig. $7 C$, bottom). EPSCs had an average amplitude of $152.6 \mathrm{pA}$ (range, 93.4-263.7 pA; $n=5$ ) and were completely blocked by $\mathrm{DH} \beta \mathrm{E}$ (Fig. $7 C$, bottom). Given our estimates of $46.7 \mathrm{pA}$ for an average unitary nEPSC response (Fig. $4 C$ ), these data indicate that on average the simultaneous activation of 3.2 individual cholinergic inputs can trigger action potentials in TRN neurons.

TRN neuronal dendrites express T-type $\mathrm{Ca}^{2+}$ channels whose activation contributes to the generation of burst firing from a relative hyperpolarized membrane potential (Huguenard and Prince, 1992). To test whether T-type $\mathrm{Ca}^{2+}$ channel activation is critical for cholinergic input-induced action potential generation, we performed cell-attached recordings from TRN neurons, and bath-applied the specific T-type $\mathrm{Ca}^{2+}$ channel blocker TTA-P2 (Dreyfus et al., 2010). We found that synaptically evoked bursting was completely blocked following bath application of TTA-P2 ( $1 \mu \mathrm{M}, 4.7 \pm 0.5$ spikes in control, 0 spikes in TTA-P2, $n=5, p<0.01$, Fig. $7 D, E$ ). In principle, the block of synaptically evoked bursting by TTA-P2 could be due to a reduction of ACh release following block of presynaptic T-type $\mathrm{Ca}^{2+}$ channels. However, TTA-P2 had no effect on nEPSC amplitude (112.8 \pm $27.8 \mathrm{pA}$ in control, $106.9 \pm 25.8 \mathrm{pA}$ in TTA-P2, $n=5, p=0.14$, Fig. $7 F$ ), indicating that $\mathrm{T}$-type $\mathrm{Ca}^{2+}$ channels are not involved in 
A Cs internal $5 \mathrm{~Hz}$

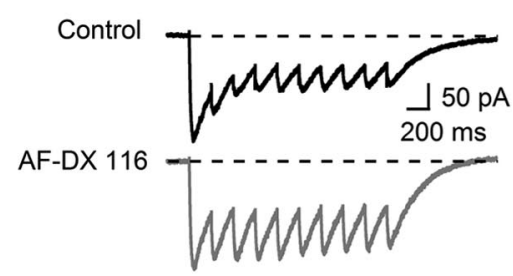

C

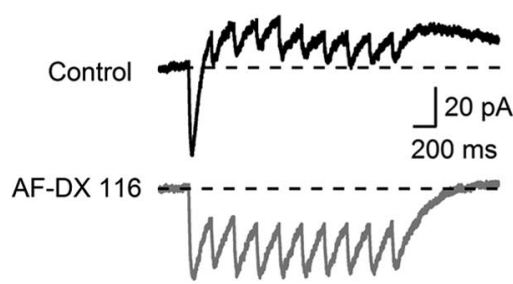

$10 \mathrm{~Hz}$

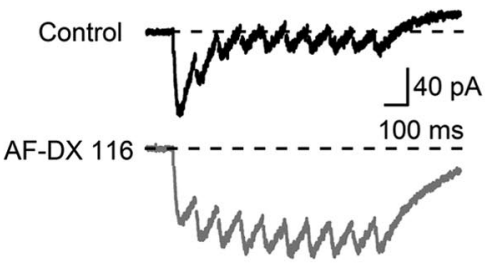

B

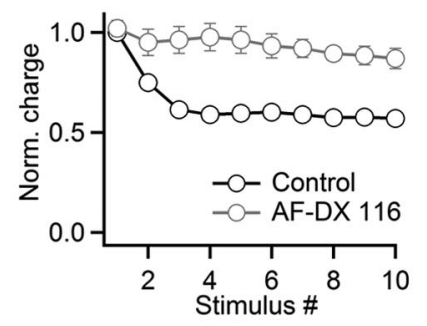

D
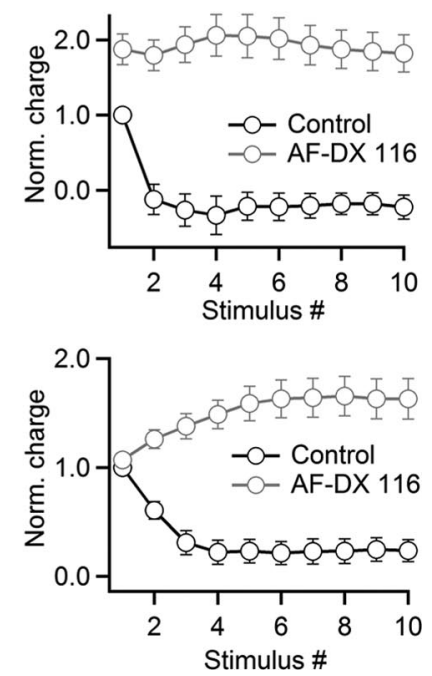

Figure 6. Presynaptic and postsynaptic muscarinic receptors control cholinergic signaling during brief stimulus trains. Recordings in $\boldsymbol{A}$ and $\boldsymbol{B}$ were done with a $\boldsymbol{C}$-based internal solution. For $\boldsymbol{C}$ and $\boldsymbol{D}$, a K-based internal solution was used. $\boldsymbol{A}, \boldsymbol{A}$ representative experiment showing $\mathrm{nEPSC}$ in response to a train of stimuli $(5 \mathrm{~Hz}, 10$ pulses) in control (black trace) and after bath application of AF-DX 116 (10 $\mu \mathrm{m}$, gray trace). $\boldsymbol{B}$, Summary data plotting synaptic charge (measured as the area underneath the voltage trace) following each stimulus, normalized to the first EPSC in control (control, black circles; AF-DX 116, gray circles). $n=5$ cells. C, Rapid suppression of nAChR-evoked excitation by mAChR activation, blocked by AF-DX 116. Representative experiments showing PSCs in response to trains of stimuli at 5 or $10 \mathrm{~Hz}$ in control (black traces) and after bath application of AF-DX 116 (10 $\mu$ m, gray traces). D, Summary data, plotting net synaptic charge (measured as the area underneath the voltage trace) following each stimulus at 5 or $10 \mathrm{~Hz}$, normalized to the net synaptic charge evoked by the first PSC in control (control, black circles; AF-DX 116, gray circles). $n=$ 8 cells for both frequencies.

triggering release of $\mathrm{ACh}$. Thus, the activation of postsynaptic T-type $\mathrm{Ca}^{2+}$ channels is critical for cholinergic input-induced burst firing.

Neurons in the TRN can generate action potentials in either burst mode or tonic mode (Llinás and Jahnsen, 1982), mediated by changes in resting membrane potential associated with different behavioral states. We tested how membrane potential influences action potential generation evoked by cholinergic synaptic inputs. TRN neurons were recorded in whole-cell mode and held in either burst mode $(-70 \mathrm{mV})$ or tonic mode $(-60 \mathrm{mV})$. In the example shown in Figure $7 G$, stimulus intensity was adjusted to elicit postsynaptic responses in $\sim 50 \%$ of all trials, suggesting threshold activation of a single axon. Activation of this input reliably triggered bursts of action potentials when the cell was held at $-70 \mathrm{mV}$, but only single spikes if the resting potential of the postsynaptic neuron was set to $-60 \mathrm{mV}$. Similar results were obtained from six additional neurons $(3.8 \pm 0.3$ spikes in burst mode, $1.1 \pm 0.1$ spikes in tonic mode, $n=7, p<0.001$, Fig. $7 H$ ). Thus, cholinergic input-evoked action potential activity is determined by the membrane potential of the postsynaptic TRN neuron.
Cholinergic synaptic inputs entrain TRN neuronal activity

Next, we tested the impact of brief trains of cholinergic synaptic activity (10 stimuli, $10 \mathrm{~Hz}$ ) on TRN neuronal firing. For a holding potential of $-60 \mathrm{mV}$, train stimuli evoked a transient postsynaptic depolarization, which gave rise to a long-lasting hyperpolarization following the end of the stimulus train (Fig. $8 A$, top). We then paired stimulus trains with action potential activity evoked by applying long depolarizing current steps (6 s, 100-140 pA) to the postsynaptic neuron (Fig. $8 A$, bottom). Cholinergic activity led to a brief increase in TRN neuronal firing at the onset of synaptic stimulation. Following this initial increase, synaptic inputs reduced action potential activity compared with baseline levels $(16.6 \pm 2.8 \mathrm{~Hz}$ in control, $8.5 \pm 1.4 \mathrm{~Hz}$ during train stimulation, $n=5$ ). Following the end of the stimulus train, spike firing was further reduced $(6.2 \pm 1.8 \mathrm{~Hz}, n=5)$ before returning to baseline levels within 1-2 s (time constant of recovery, $528 \pm 205$ ms; $n=5$ ). Interestingly, synaptic stimulation tightly entrained spike firing, such that spike probability peaked within a $20 \mathrm{~ms}$ window following individual synaptic stimuli (Fig. $8 B$ ). Across all neurons examined $(n=5)$, spike probability before synaptic stimulation was $0.34 \pm 0.06$ (bin size, $20 \mathrm{~ms}$ ). For the last five stimuli of the stimulus train, spike probability immediately following each synaptic stimulus $(0-20 \mathrm{~ms})$ was $0.42 \pm 0.12$, before dropping to $0.09 \pm$ 0.02 (40-60 ms).

To better understand the role of nAChR and mAChR activation in controlling TRN firing, we performed experiments in which each receptor type was blocked individually. Blocking postsynaptic nAChRs via bath application of $\mathrm{DH} \beta \mathrm{E}(3 \mu \mathrm{M})$ dramatically reduced action potential activity during the stimulus train compared with control, resulting in long pauses of spike firing (Fig. $8 C, n=3$ ). By contrast, when both presynaptic and postsynaptic mAChRs were blocked by bath applying AF-DX 116, spike firing moderately increased during synaptic stimulation, but spike entrainment to synaptic activity was no longer apparent (Fig. $8 D, n=2$ ). Together, these data suggest that the combined activation of nAChRs and mAChRs during cholinergic afferent activity at physiologically realistic rates can lead to the precise entrainment of TRN neuronal firing.

\section{Discussion}

An increasing number of studies have shown that cholinergic synaptic transmission mediated by $\mathrm{nAChRs}$ is more prominent than previously appreciated (Zhang et al., 1993; Hatton and Yang, 2002; Letzkus et al., 2011; Arroyo et al., 2012; English et al., 2012). Here we demonstrate that in the TRN, cholinergic synaptic signaling is mediated by the activation of both nAChRs and mAChRs, leading to E-I postsynaptic responses. Synaptically 

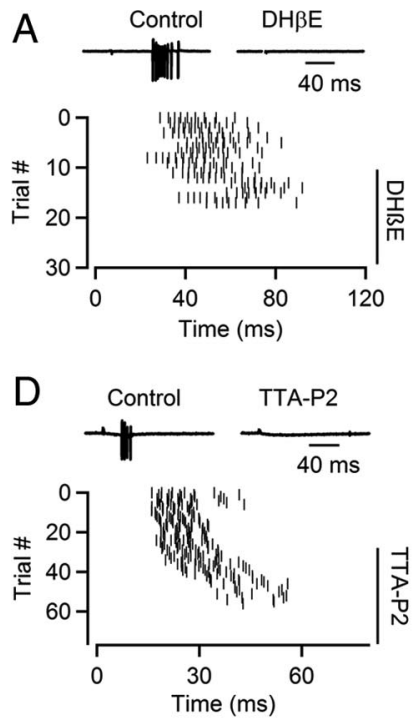

G

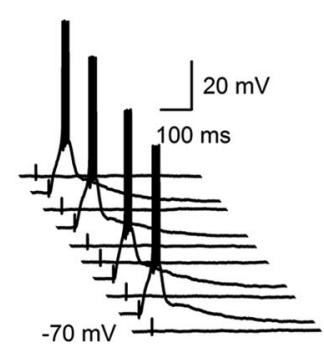

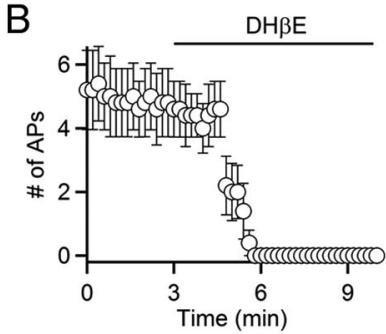

$\mathrm{E}$

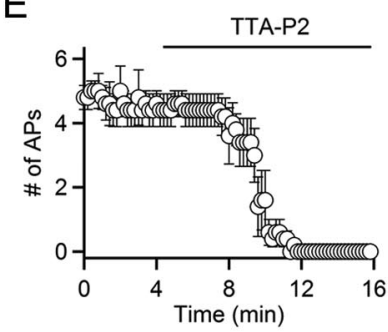

B

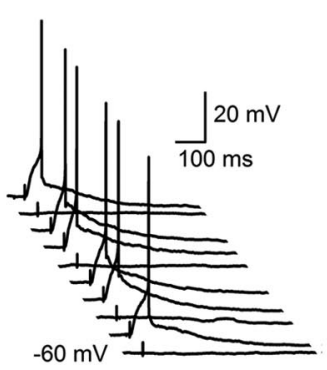

C

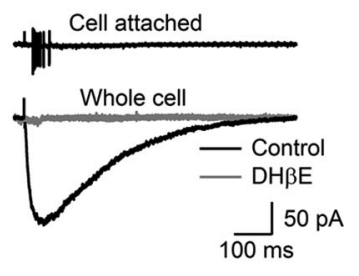

$\mathrm{F}$

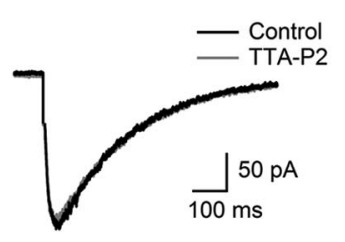

$\mathrm{H}$

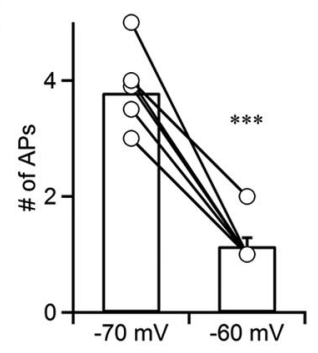

Figure 7. Cholinergic synaptic inputs trigger action potentials in TRN neurons. $A$, Top, Synaptically evoked action potentials in a TRN neuron recorded in loose-patch mode, blocked by application of $\mathrm{DH} \beta \mathrm{E}(300 \mathrm{~nm})$. Bottom, Raster plot showing the timing of spikes evoked by single stimuli applied at $t=0 \mathrm{~ms}$ before and during bath application of $\mathrm{DH} \beta \mathrm{E}$ ( $300 \mathrm{~nm})$. $\boldsymbol{B}$, Time course of $\mathrm{DH} \beta \mathrm{E}$-induced block of synaptically evoked action potential firing ( $n=5$ neurons). C, Top, Single stimulus elicits burst of action potentials in a TRN neuron recorded in cell-attached configuration, using a (s-based internal solution. Bottom, For the same neuron recorded in whole-cell voltage clamp, stimulation at the same intensity evoked an nEPSC that was blocked by DH $\beta E$ ( $300 \mathrm{~nm}$ ). D, Top, Synaptically evoked action potentials in a TRN neuron recorded in loose-patch mode, blocked by the specific T-type $\mathrm{Ca}^{2+}$ channel antagonist TTA-P2 (1 $\left.\mu \mathrm{M}\right)$. Bottom, Raster plot showing the timing of spikes evoked by single stimuli applied at $t=0 \mathrm{~ms}$ before and during bath application of TTA-P2 $(1 \mu \mathrm{M})$. E, Summary data showing the time course of the TTA-P2-induced block of synaptically evoked action potential firing in TRN neurons ( $n=5$ neurons). $F$, ACh release is not influenced by TTA-P2. A representative experiment showing an nEPSC in control (black) and following bath application of TTA-P2 (1 $\mu \mathrm{m}$, gray). TRN neurons were recorded in whole-cell voltage clamp with a Cs-based internal solution. Traces are averages of $20-30$ individual trials. $\boldsymbol{G}, \boldsymbol{H}$, Resting membrane potential determines ACh-induced spiking in TRN neurons. Neurons were recorded in current clamp with a K-based internal solution. A representative experiment shows trials with response successes and failures, evoked by fixed stimulus intensity, indicating activation of a single cholinergic axon (G). Bursts were evoked at a holding potential of $-70 \mathrm{mV}$ ( $\mathbf{G}$, left), and single spikes at a holding potential of $-60 \mathrm{mV}(\boldsymbol{G}$, right). Summary plot showing that cholinergic synaptic inputs trigger action potentials in a state-dependent manner $(\boldsymbol{H})$. Data include single-fiber and multiple-fiber responses. ${ }^{* *} p<0.001$, paired Student's $t$ test. $n=7$.

released ACh also activates presynaptic mAChRs, thereby controlling cholinergic signaling during ongoing activity via autoinhibition. In addition, we show that even a small number of cholinergic afferents can trigger spike activity in postsynaptic TRN neurons. Furthermore, we find that brief trains of cholinergic synaptic activity can reliably entrain TRN neuronal firing. Our findings highlight several novel mechanisms underlying cholinergic transmission in the mammalian CNS.

\section{Properties of cholinergic synaptic transmission in the TRN}

Our demonstration of reliable cholinergic responses in TRN neurons evoked by individual stimuli is in agreement with the idea that ACh signaling occurs via conventional synapses. This is supported by previous anatomical work demonstrating the existence of ultrastructurally defined synaptic contacts formed by cholinergic afferents, in particular on distal dendrites of TRN neurons (Hallanger and Wainer, 1988; Parent and Descarries, 2008). The functional expression of both nAChRs and mAChRs in TRN dendrites has been known for some time (McCormick and Prince, 1986; Lee and McCormick, 1995). However, the spatial relation- ship of presynaptic cholinergic terminals and postsynaptic cholinergic receptors is not well understood. Our data indicate that release of ACh from individual axons activates nAChRs and $\mathrm{mAChRs}$ coexpressed in the postsynaptic membrane, although we cannot rule out the possibility that TRN neurons express only nAChRs or mAChRs near individual release sites. We found that nEPSCs evoked by stimulation of individual axons display relatively large average amplitudes, with unusually low amplitude variability from trial to trial, and a complete lack of response failures. This argues that individual afferents contact a given postsynaptic neuron via a large number of release sites, and that release probability $p$ is high, at least during low stimulus frequencies.

While our results are most readily explained by cholinergic signaling via conventional synapses, other forms of nonsynaptic fast signaling cannot be excluded (Szapiro and Barbour, 2007; Sarter et al., 2009). The expression of AChE relative to sites of ACh release is not known, so it is possible that synaptically released ACh can diffuse and act on more distant sites before degrading. Such a scenario seems to be supported by a slightly longer response latency compared with that of AMPAR- 
A
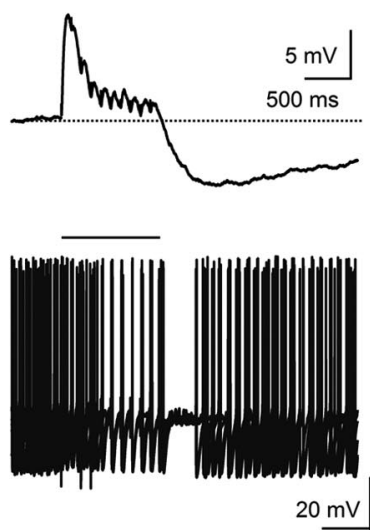

$500 \mathrm{~ms}$
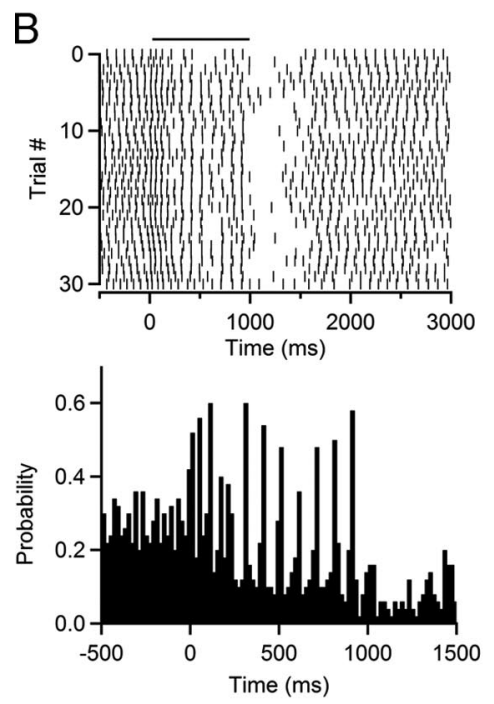
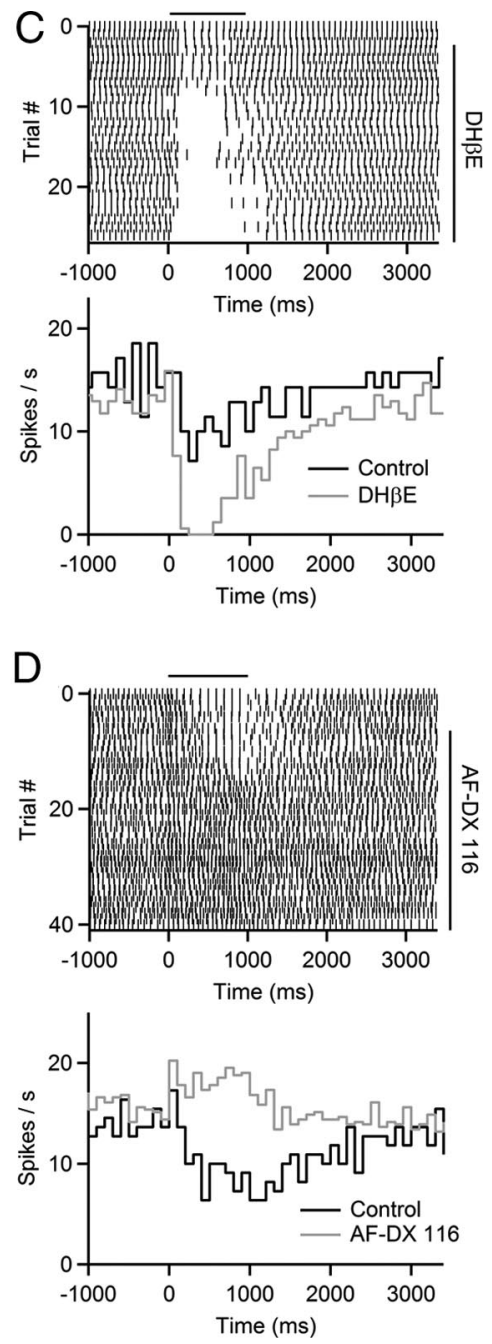

Figure 8. Cholinergic synaptic inputs entrain TRN neuronal activity. Neurons were recorded with a K-based internal solution and held in current clamp. $\boldsymbol{A}$, Top, Postsynaptic E-I response evoked by a brief stimulus train (10 stimuli, $10 \mathrm{~Hz}$ ), for a TRN neuron held at $-60 \mathrm{mV}$. Bottom, The same stimulus train (indicated by horizontal bar) was applied during ongoing action potential activity evoked by depolarizing current steps $(6 \mathrm{~s}, 120 \mathrm{pA})$. Shown are five consecutive trials. $\boldsymbol{B}$, Top, Raster plot showing the timing of spikes in consecutive trials during and following stimulus train (onset of synaptic stimulation at $t=0 \mathrm{~ms}$ ) for same cell as shown in $\boldsymbol{A}$. Bottom, Poststimulus time histogram (PSTH; bin size, $20 \mathrm{~ms}$ ) compiled for 58 consecutive trials. $\boldsymbol{C}$, In a different neuron, spike entrainment to cholinergic stimulation was eliminated by blocking nAChRs. Top, Raster plot showing timing of spikes during stimulus train (10 stimuli, $10 \mathrm{~Hz}$ ) before and following bath application of the nAChR antagonist DH $\beta \mathrm{E}(3 \mu \mathrm{m})$. Bottom, PSTH (bin size, $100 \mathrm{~ms}$ ) for spike firing in control (black) and following bath application of $\mathrm{DH} \beta \mathrm{E}$ (gray). D, Block of spike entrainment by pharmacological block of M2 muscarinic receptors. Top, Raster plot showing timing of spikes during stimulus train (10 stimuli, 10 $\mathrm{Hz}$ ) before and following bath application of the mAChR antagonist AF-DX $116(10 \mu \mathrm{m})$. Bottom, PSTH (bin size, $100 \mathrm{~ms}$ ) for spike firing in control (back) and following bath application of AF-DX 116 (gray).

mediated EPSCs, a slow nEPSC rise time, and a low nEPSC amplitude variability from trial to trial (Szapiro and Barbour, 2007). However, the fact that postsynaptic cholinergic responses can be detected following single stimuli applied to individual presynaptic axons places significant constraints on the synaptic ultrastructure underlying cholinergic signaling.

The presence of fast cholinergic signaling does not exclude a role of slower, more widespread forms of signaling. The majority of cholinergic terminals found in TRN do not form synaptic contacts with dendritic processes (Parent and Descarries, 2008). It is possible that release from such terminals as well as from conventional release sites, especially following sustained highfrequency afferent activity, leads to a spatially more widespread and longer-lasting ACh signal, leading to the activation of more distant targets, such as extrasynaptic cholinergic receptors ex-

pressed in dendrites, or receptors expressed in nearby glutamatergic or GABAergic presynaptic terminals and axons (Kawai et al., 2007).

Spike generation by cholinergic inputs We found that the activation of cholinergic inputs is sufficient to generate action potentials in TRN neurons. Given our estimates of both unitary synaptic responses as well as synaptic response amplitudes sufficient to trigger action potential firing, we estimate that the number of unitary inputs necessary to trigger action potentials is 3.2 on average, arguing that cholinergic input-induced spike generation is a physiologically realistic mechanism.

When TRN neurons were held in burst mode, cholinergic input-evoked spike generation required activation of postsynaptic T-type $\mathrm{Ca}^{2+}$ channels, as burst activity was completely eliminated by a T-type $\mathrm{Ca}^{2+}$ channel blocker. This extends our previous findings demonstrating that intra-TRN GABAergic synapses generate $\mathrm{GABA}_{\mathrm{A}}$ receptor-mediated depolarizations in TRN neurons, which like nEPSPs are amplified by T-type $\mathrm{Ca}^{2+}$ channel activation to generate bursts of action potentials (Sun et al., 2012). Anatomical studies have shown that cholinergic synapses target the distal dendrites of TRN neurons, which show strong expression of T-type $\mathrm{Ca}^{2+}$ channels (Crandall et al., 2010). Our data therefore suggest that nEPSPs initiate local $\mathrm{Ca}^{2+}$ spikes in TRN dendrites, which then spread toward the $\mathrm{Na}^{+}$spike initiation zone in the axon.

\section{E-I signaling mediated by $\mathrm{ACh}$ release}

The central finding of our study is that release of $\mathrm{ACh}$ from individual axons leads to the reliable activation of both ionotropic and metabotropic ACh receptors and the generation of a biphasic response, in which excitation, mediated by nAChR opening, is followed by inhibition, mediated by opening of GIRK conductances linked to $\mathrm{mAChR}$ activation. Importantly, both excitation and inhibition are evoked by the same low-frequency afferent input. Cholinergic E-I signaling with similar stimulus requirements has been previously demonstrated in several systems, such as cholinergic synapses onto interneurons in Aplysia (Blankenship et al., 1971), transient feedback projections to inner hair cells in the neonatal mammalian cochlea (Glowatzki and Fuchs, 2000), and afferent inputs to the superior cervical ganglion (Yarosh et al., 1988). Few well documented reports exist for other neurotransmitter systems. Glutamate, in addition to evoking fast excitation by binding to ionotropic receptors, can generate an inhibitory response at synapses in the midbrain (Fiorillo and Williams, 1998) and olfactory bulb (Isaacson and Murphy, 2001), triggered by the activation of metabotropic glutamate receptors and NMDA receptors, respectively. No- 
tably, in these cases, the generation of the inhibitory response requires sustained afferent activity, suggesting that transmitter pooling and spillover from the synaptic cleft are necessary to activate extrasynaptically expressed receptors.

What are the functional roles of E-I signaling in the TRN? Although preliminary, our data (Fig. 8) strongly indicate that brief trains of cholinergic afferent activity can lead to the rapid and precise entrainment of TRN neuronal firing. It is likely that neighboring TRN neurons share common input from a number of individual cholinergic axons. TRN neurons form local clusters interconnected by electrical synapses (Long et al., 2004), which have low-pass filter properties and therefore seem well suited to propagate slow signals generated by postsynaptic nAChR and $\mathrm{mAChR}$ activation. Thus, cholinergic afferent activity during periods of arousal could play a role in transiently synchronizing local TRN neuronal firing.

More generally, E-I signaling is likely critical for the rapid and precise control of the postsynaptic integration of glutamatergic and GABAergic synaptic inputs in TRN dendrites. For example, glutamatergic EPSPs generated within $\sim 100$ ms following cholinergic synapse activation will summate with the nEPSP, enhancing the likelihood of triggering an action potential. For glutamatergic input arriving between $\sim 150$ and $1500 \mathrm{~ms}$ following cholinergic synapse activation (i.e., during the muIPSP), the effect could be more complex. Opening of GIRK conductances following $\mathrm{mAChR}$ activation enhances membrane conductance, which will effectively shunt weak glutamatergic inputs. However, GIRK opening will also lead to a strong deinactivation of T-type $\mathrm{Ca}^{2+}$ channels by hyperpolarizing distal dendrites. Thus, strong glutamatergic inputs, which under control conditions only trigger individual spikes, will likely trigger bursts of action potentials, due to activation of T-type $\mathrm{Ca}^{2+}$ channels from a hyperpolarized membrane potential (McCormick and Prince, 1986). In this way, muIPSPs might create precise temporal windows, during which glutamatergic inputs are differentially processed in TRN dendrites, depending on their strength. Such a role of postsynaptic M2 mAChRs in controlling spike generation is consistent with a previous finding showing that pharmacological activation of M2 mAChRs in thalamic GABAergic interneurons can control spike generation, depending on the strength of sensory input (Antal et al., 2010). More generally, the relative timing of glutamatergic and cholinergic inputs might determine distinct forms of heterosynaptic plasticity, as has been shown for cholinergic and glutamatergic synapses in the hippocampal CAl region $(\mathrm{Gu}$ and Yakel, 2011).

Previous work examining the role of ACh in the thalamus has emphasized long-lasting and widespread changes in membrane excitability and transmitter release, mediated by diffuse transmission and slow changes in the ambient levels of ACh. In marked contrast to this view, our study highlights the presence of rapid and precise cholinergic signaling in the TRN. Future studies will address whether such forms of cholinergic transmission exist in other thalamic nuclei.

\section{References}

Agmon A, Connors BW (1991) Thalamocortical responses of mouse somatosensory (barrel) cortex in vitro. Neuroscience 41:365-379. CrossRef Medline

Antal M, Acuna-Goycolea C, Pressler RT, Blitz DM, Regehr WG (2010) Cholinergic activation of M2 receptors leads to context-dependent modulation of feedforward inhibition in the visual thalamus. PLoS Biol 8:e1000348. CrossRef Medline

Arroyo S, Bennett C, Aziz D, Brown SP, Hestrin S (2012) Prolonged disynaptic inhibition in the cortex mediated by slow, non- $\alpha 7$ nicotinic excita- tion of a specific subset of cortical interneurons. J Neurosci 32: 3859-3864. CrossRef Medline

Blankenship JE, Wachtel H, Kandel ER (1971) Ionic mechanisms of excitatory, inhibitory, and dual synaptic actions mediated by an identified interneuron in abdominal ganglion of Aplysia. J Neurophysiol 34:76-92. Medline

Boucetta S, Jones BE (2009) Activity profiles of cholinergic and intermingled GABAergic and putative glutamatergic neurons in the pontomesencephalic tegmentum of urethane-anesthetized rats. J Neurosci 29: 4664-4674. CrossRef Medline

Crandall SR, Govindaiah G, Cox CL (2010) Low-threshold $\mathrm{Ca}^{2+}$ current amplifies distal dendritic signaling in thalamic reticular neurons. J Neurosci 30:15419-15429. CrossRef Medline

Crick F (1984) Function of the thalamic reticular complex: the searchlight hypothesis. Proc Natl Acad Sci U S A 81:4586-4590. CrossRef Medline

Dani JA, Bertrand D (2007) Nicotinic acetylcholine receptors and nicotinic cholinergic mechanisms of the central nervous system. Annu Rev Pharmacol Toxicol 47:699-729. CrossRef Medline

Deisz RA, Prince DA (1989) Frequency-dependent depression of inhibition in guinea-pig neocortex in vitro by GABAB receptor feed-back on GABA release. J Physiol 412:513-541. Medline

Descarries L, Gisiger V, Steriade M (1997) Diffuse transmission by acetylcholine in the CNS. Prog Neurobiol 53:603-625. CrossRef Medline

Dreyfus FM, Tscherter A, Errington AC, Renger JJ, Shin HS, Uebele VN, Crunelli V, Lambert RC, Leresche N (2010) Selective T-type calcium channel block in thalamic neurons reveals channel redundancy and physiological impact of $\mathrm{I}_{\text {Twindow. }}$ J Neurosci 30:99-109. CrossRef Medline

English DF, Ibanez-Sandoval O, Stark E, Tecuapetla F, Buzsáki G, Deisseroth K, Tepper JM, Koos T (2012) GABAergic circuits mediate the reinforcement-related signals of striatal cholinergic interneurons. Nat Neurosci 15:123-130. CrossRef Medline

Fiorillo CD, Williams JT (1998) Glutamate mediates an inhibitory postsynaptic potential in dopamine neurons. Nature 394:78-82. CrossRef Medline

Glowatzki E, Fuchs PA (2000) Cholinergic synaptic inhibition of inner hair cells in the neonatal mammalian cochlea. Science 288:2366-2368. CrossRef Medline

Gu Z, Yakel JL (2011) Timing-dependent septal cholinergic induction of dynamic hippocampal synaptic plasticity. Neuron 71:155-165. CrossRef Medline

Hallanger AE, Wainer BH (1988) Ultrastructure of ChAT-immunoreactive synaptic terminals in the thalamic reticular nucleus of the rat. J Comp Neurol 278:486-497. CrossRef Medline

Hartings JA, Temereanca S, Simons DJ (2003) State-dependent processing of sensory stimuli by thalamic reticular neurons. J Neurosci 23:52645271. Medline

Hatton GI, Yang QZ (2002) Synaptic potentials mediated by $\alpha 7$ nicotinic acetylcholine receptors in supraoptic nucleus. J Neurosci 22:29-37. Medline

Higley MJ, Gittis AH, Oldenburg IA, Balthasar N, Seal RP, Edwards RH, Lowell BB, Kreitzer AC, Sabatini BL (2011) Cholinergic interneurons mediate fast VGluT3-dependent glutamatergic transmission in the striatum. PLoS One 6:e19155. CrossRef Medline

Hu B, Steriade M, Deschenes M (1989) The effects of brainstem peribrachial stimulation on perigeniculate neurons: the blockage of spindle waves. Neuroscience 31:1-12. CrossRef Medline

Huguenard JR, Prince DA (1992) A novel T-type current underlies prolonged $\mathrm{Ca}^{2+}$-dependent burst firing in GABAergic neurons of rat thalamic reticular nucleus. J Neurosci 12:3804-3817. Medline

Hurst RS, Hajós M, Raggenbass M, Wall TM, Higdon NR, Lawson JA, Rutherford-Root KL, Berkenpas MB, Hoffmann WE, Piotrowski DW, Groppi VE, Allaman G, Ogier R, Bertrand S, Bertrand D, Arneric SP (2005) A novel positive allosteric modulator of the $\alpha 7$ neuronal nicotinic acetylcholine receptor: in vitro and in vivo characterization. J Neurosci 25:4396-4405. CrossRef Medline

Isaacson JS, Murphy GJ (2001) Glutamate-mediated extrasynaptic inhibition: direct coupling of NMDA receptors to $\mathrm{Ca}(2+)$-activated $\mathrm{K}+$ channels. Neuron 31:1027-1034. CrossRef Medline

Jones EG (2007) The thalamus, 2nd edition. New York: Cambridge UP.

Kawai H, Lazar R, Metherate R (2007) Nicotinic control of axon excitability regulates thalamocortical transmission. Nat Neurosci 10:1168-1175. CrossRef Medline 
Kim U, Sanchez-Vives MV, McCormick DA (1997) Functional dynamics of GABAergic inhibition in the thalamus. Science 278:130-134. CrossRef Medline

Lee KH, McCormick DA (1995) Acetylcholine excites GABAergic neurons of the ferret perigeniculate nucleus through nicotinic receptors. J Neurophysiol 73:2123-2128. Medline

Letzkus JJ, Wolff SB, Meyer EM, Tovote P, Courtin J, Herry C, Lüthi A (2011) A disinhibitory microcircuit for associative fear learning in the auditory cortex. Nature 480:331-335. CrossRef Medline

Llinás R, Jahnsen H (1982) Electrophysiology of mammalian thalamic neurones in vitro. Nature 297:406-408. CrossRef Medline

Long MA, Landisman CE, Connors BW (2004) Small clusters of electrically coupled neurons generate synchronous rhythms in the thalamic reticular nucleus. J Neurosci 24:341-349. CrossRef Medline

Lüscher C, Jan LY, Stoffel M, Malenka RC, Nicoll RA (1997) G proteincoupled inwardly rectifying $\mathrm{K}+$ channels (GIRKs) mediate postsynaptic but not presynaptic transmitter actions in hippocampal neurons. Neuron 19:687-695. CrossRef Medline

McAlonan K, Cavanaugh J, Wurtz RH (2006) Attentional modulation of thalamic reticular neurons. J Neurosci 26:4444-4450. CrossRef Medline

McCormick DA (1989) Cholinergic and noradrenergic modulation of thalamocortical processing. Trends Neurosci 12:215-221. CrossRef Medline

McCormick DA (1992) Neurotransmitter actions in the thalamus and cerebral cortex and their role in neuromodulation of thalamocortical activity. Prog Neurobiol 39:337-388. CrossRef Medline

McCormick DA, Bal T (1997) Sleep and arousal: thalamocortical mechanisms. Annu Rev Neurosci 20:185-215. CrossRef Medline

McCormick DA, Prince DA (1986) Acetylcholine induces burst firing in thalamic reticular neurones by activating a potassium conductance. Nature 319:402-405. CrossRef Medline

Miwa JM, Freedman R, Lester HA (2011) Neural systems governed by nicotinic acetylcholine receptors: emerging hypotheses. Neuron 70:20-33. CrossRef Medline

Oda S, Sato F, Okada A, Akahane S, Igarashi H, Yokofujita J, Yang J, Kuroda M (2007) Immunolocalization of muscarinic receptor subtypes in the reticular thalamic nucleus of rats. Brain Res Bull 74:376-384. CrossRef Medline

Parent M, Descarries L (2008) Acetylcholine innervation of the adult rat thalamus: distribution and ultrastructural features in dorsolateral geniculate, parafascicular, and reticular thalamic nuclei. J Comp Neurol 511:678-691. CrossRef Medline
Perkins KL (2006) Cell-attached voltage-clamp and current-clamp recording and stimulation techniques in brain slices. J Neurosci Methods 154: 1-18. CrossRef Medline

Pinault D (2004) The thalamic reticular nucleus: structure, function and concept. Brain Res Brain Res Rev 46:1-31. Medline

Ren J, Qin C, Hu F, Tan J, Qiu L, Zhao S, Feng G, Luo M (2011) Habenula "cholinergic" neurons co-release glutamate and acetylcholine and activate postsynaptic neurons via distinct transmission modes. Neuron 69: 445-452. CrossRef Medline

Sarter M, Parikh V, Howe WM (2009) Phasic acetylcholine release and the volume transmission hypothesis: time to move on. Nat Rev Neurosci 10:383-390. CrossRef Medline

Scanziani M, Salin PA, Vogt KE, Malenka RC, Nicoll RA (1997) Usedependent increases in glutamate concentration activate presynaptic metabotropic glutamate receptors. Nature 385:630-634. CrossRef Medline

Sun YG, Wu CS, Renger JJ, Uebele VN, Lu HC, Beierlein M (2012) GABAergic synaptic transmission triggers action potentials in thalamic reticular nucleus neurons. J Neurosci 32:7782-7790. CrossRef Medline

Szapiro G, Barbour B (2007) Multiple climbing fibers signal to molecular layer interneurons exclusively via glutamate spillover. Nat Neurosci 10: 735-742. CrossRef Medline

Tallini YN, Shui B, Greene KS, Deng KY, Doran R, Fisher PJ, Zipfel W, Kotlikoff MI (2006) BAC transgenic mice express enhanced green fluorescent protein in central and peripheral cholinergic neurons. Physiol Genomics 27:391-397. CrossRef Medline

Wu CS, Zhu J, Wager-Miller J, Wang S, O'Leary D, Monory K, Lutz B, Mackie $\mathrm{K}, \mathrm{Lu} \mathrm{HC}$ (2010) Requirement of cannabinoid CB(1) receptors in cortical pyramidal neurons for appropriate development of corticothalamic and thalamocortical projections. Eur J Neurosci 32:693-706. CrossRef Medline

Yamasaki M, Matsui M, Watanabe M (2010) Preferential localization of muscarinic M1 receptor on dendritic shaft and spine of cortical pyramidal cells and its anatomical evidence for volume transmission. J Neurosci 30:4408-4418. CrossRef Medline

Yarosh CA, Acosta CG, Ashe JH (1988) Modification of nicotinic ganglionic transmission by muscarinic slow postsynaptic potentials in the in vitro rabbit superior cervical ganglion. Synapse 2:174-182. CrossRef Medline

Zhang M, Wang YT, Vyas DM, Neuman RS, Bieger D (1993) Nicotinic cholinoceptor-mediated EPSPs in rat nucleus ambiguus. Exp Brain Res 96:83-88. Medline 